\title{
Validasi Modul Pelatihan Disiplin Positif untuk Meningkatkan Praktik Pengasuhan pada Ibu Anak Prasekolah
}

\author{
Wijayanti Retnaningsih ${ }^{1} \mathcal{E}$ Diana Setiyawati ${ }^{2}$ \\ 1,2Fakultas Psikologi Universitas Gadjah Mada
}

\begin{abstract}
This study aimed to validate Positive Discipline Training Module to improve parenting practice. Module validation is conducted through two stages. The first is of content validation which consisted of: 1) validation of contents on materials, methods, media, activities, worksheets, and time used in module, 2) validation of contents about legibility of module for family planning counselors) and two functional validation stages: 1) training of trainer (ToT) for family planning counselors and 2) training of Positive Discipline in mothers of preschool children. The result of the first stage content validity coefficient ranged between 0.750-0.958. The result of the second stage content validity ranged between $0.70-0.95$. The result of ToT indicated that it could improve positive discipline knowledge on family planning counselors $(Z$ $=-2.032, p=0.042)$. Mann Whitney $U$ test showed that Positive Discipline Training could improve the practice of parenting in the experimental group $(U=0.000, p<0.01)$. Thus, the module had sufficient content and functional validity. This research concluded that Positive Discipline Training Module is valid for improving parenting practice for mothers of the preschool children with family planning counselor trainers.
\end{abstract}

Keywords: family planning counselors; module validation; parenting practice; positive discipline training; preschool children

Abstrak. Penelitian ini bertujuan memvalidasi Modul Pelatihan Disiplin Positif untuk meningkatkan praktik pengasuhan. Validasi modul dilakukan melalui dua tahap. Pertama adalah validasi isi: 1) validasi materi, metode, media, aktivitas, lembar kerja dan waktu yang digunakan dalam modul, dan 2) validasi keterbacaan modul bagi Penyuluh Keluarga Berencana. Lalu terdapat dua tahap validasi fungsional: 1) training of trainer (ToT) Pelatihan Disiplin Positif bagi Penyuluh Keluarga Berencana, dan 2) Pelatihan Disiplin Positif pada ibu anak prasekolah. Hasil koefisien validitas isi tahap pertama berkisar antara 0,750-0,958. Hasil koefisien validitas isi tahap kedua berkisar antara 0,70-0,95. Untuk validasi fungsional, hasil dari ToT menunjukkan bahwa ToT dapat meningkatkan pengetahuan disiplin positif pada Penyuluh Keluarga Berencana $(Z=-2,032, p=0,042)$. Hasil uji Mann Whitney $U$ menunjukkan bahwa Pelatihan Disiplin Positif dapat meningkatkan praktik pengasuhan pada kelompok eksperimen $(U=0,000, p<0,01)$. Hal tersebut menunjukkan bahwa modul memiliki validitas konten dan fungsional yang memadai. Dapat disimpulkan bahwa Modul Pelatihan Disiplin Positif valid untuk meningkatkan praktik pengasuhan pada ibu anak prasekolah dengan trainer Penyuluh Keluarga Berencana.

Kata kunci: anak prasekolah; pelatihan disiplin positif; penyuluh keluarga berencana; praktik pengasuhan; validasi modul

${ }^{1}$ Korespondensi mengenai artikel ini dapat dilakukan melalui hanggar.wijaya@gmail.com ${ }^{2}$ atau diana_psy@ugm.ac.id 
Pengasuhan merupakan komponen utama yang mendorong baik buruknya pertumbuhan, perkembangan, dan pembentukan kepribadian seseorang (Bornstein, 2007; Santrock, 2013). Melalui pengasuhan yang berkualitas diprediksi mampu membentuk manusia yang sehat, cerdas, dan produktif yang merupakan modal yang berharga bagi pembangunan bangsa (Kementerian Hukum dan Hak Asasi Manusia Republik Indonesia, 2013).

Berbagai hasil penelitian menunjukkan bahwa anak yang tumbuh dalam pengasuhan yang lembut dan tegas menunjukkan perkembangan kognisi, konsep diri, kontrol diri, kemampuan komunikasi kompetensi sosial, memiliki kesiapan sekolah, motivasi berprestasi, dan performansi akademik yang lebih baik (Huey, Sayler, \& Rinn, 2013). Selain itu, anak juga menunjukkan perkembangan emosi yang lebih baik (Alegre, 2012), dan tidak rentan mengalami permasalahan perilaku dan emosi (Hasan, Hyson \& Chang, 2013; McKee, Colletti, Rakow, Jones, \& Forehand, 2008; Rinaldi \& Howe, 2012; Situmorang, 2015).

Sayangnya, hasil reviu yang dilakukan oleh World Bank menunjukkan masih banyak orang tua di Indonesia yang menerapkan praktik pengasuhan yang kurang tepat dalam mendisiplinkan anak. Orang tua masih sering menunjukkan sikap otoriter atau permisif ketika mendisiplinkan anak mereka (Tomlinson \& Andina, 2015). Penyebab utama orang tua mendisiplinkan anak dengan cara yang kurang baik dikarenakan kurangnya pengetahuan mengenai perkembangan anak, pengetahuan mengenai pengasuhan yang tepat (Sanders, 2008; Sasongko, 2015) dan kurangnya kemampuan orang tua dalam meregulasi emosi (Bögels \& Restifo, 2014).
Sesuai dengan rekomendasi dari American Psychological Association, World Health Organization (Sanders, 2012) dan United Stated Centers for Disease Control and Prevention (Mercy \& Saul, 2009) peningkatan kualitas pengasuhan dapat dilakukan dengan cara memberikan pelatihan pengasuhan orang tua. Dari beberapa program pelatihan pengasuhan orang tua yang ada, pelatihan disiplin positif dianggap sebagai salah satu program yang tepat untuk mengatasi permasalahan banyaknya orang tua yang tidak mampu menyeimbangkan pemberian dukungan dan kontrol dalam mendisiplinkan anak (Olson, DeFrain \& Skogrand, 2014).

Pelatihan disiplin positif terbukti dapat digunakan sebagai upaya preventif dan promotif untuk meningkatkan kesehatan mental pada komunitas (Gfroerer, Nelsen \& Kern, 2013). Orang tua yang mendapatkan pelatihan disiplin positif menunjukkan kemampuan komunikasi yang lebih baik dalam memberikan batasan pada anak, menjadi lebih tahu mengenai perkembangan anak dan mengarahkan anak tanpa kekerasan (Ródenas, Garcés, Durá, \& DoñateMartínez, 2014). Holliday (2014) juga mengungkapkan bahwa pelatihan orang tua dengan konsep disiplin positif terbukti dapat meningkatkan pola pengasuhan otoritatif dan menurunkan pola pengasuhan permisif dan otoriter sehingga anak dapat berkembang dengan lebih baik.

Mengingat pentingnya peran pengasuhan dalam penyiapan generasi penerus bangsa yang berkualitas, maka usaha peningkatan kualitas pengasuhan tidak hanya merupakan tanggung jawab orang tua. Negara dan masyarakat memiliki peran penting dalam menunjang dan mendorong pemberian pengasuhan yang 
berkualitas bagi anak. Sebenarnya, pemerintah Indonesia sudah memiliki beberapa program pendidikan pengasuhan bagi orang tua. Diantaranya adalah Kelas Ibu (Kementerian Kesehatan), Bina Keluarga Balita (Badan Kependudukan dan Keluarga Berencana Nasional/BKKBN), Taman Anak Sejahtera dan Program Keluarga Harapan (Kementerian Sosial) serta Program Anak Usia Dini dan keterlibatan orang tua dalam pendidikan (Kementerian Pendidikan dan Kebudayaan). Akan tetapi, hasil reviu yang dilakukan oleh World Bank terhadap program pengasuhan yang ada di Indonesia menunjukkan bahwa secara konten, program-program pengasuhan yang ada di Indonesia dirasa kurang efektif dikarenakan lebih terfokus pada kesehatan fisik dibandingkan dengan perkembangan kognitif dan sosial-emosional serta terlalu banyak memuat materi yang kurang terstruktur dengan baik (Tomlinson \& Andina, 2015).

Agar pendidikan pengasuhan bagi orang tua di Indonesia lebih baik maka perlu disusun materi pendidikan orang tua yang tidak terlalu luas cakupannya namun terencana dengan baik. Untuk mengatasi permasalahan banyaknya orang tua Indonesia yang menerapkan pengasuhan yang kurang tepat dalam mendisiplinkan anak, World Bank merekomendasikan adanya penyusunan materi mengenai strategi teknik disiplin tanpa kekerasan yang efektif yang disusun secara terstruktur (Tomlinson \& Andina, 2015).

Sesuai dengan Undang-undang Nomor 52 tahun 2009 pada pasal 56 ayat (2), disebutkan bahwa Badan Kependudukan dan Keluarga Berencana Nasional (BKKBN) merupakan lembaga pemerintah yang berperan penting dalam upaya mewujudkan keluarga berencana dan kesejahteraan keluarga. Di lapangan, implementasi, pelaksanaan dan pengelolaan program $\mathrm{BKKBN}$ menjadi tanggung jawab Penyuluh Keluarga Berencana/ PKB (Badan Kependudukan dan Keluarga Berencana Nasional (BKKBN), 2014).

Penyuluh Keluarga Berencana yang merupakan pengelola dan pelaksana program BKKBN yang langsung bersentuhan dengan masyarakat, hendaknya memiliki kemampuan untuk memberikan pelayanan memberikan informasi, mengedukasi, dan mengadvokasi masyarakat untuk menerapkan disiplin positif dalam pengasuhan sebagai salah satu strategi yang dapat digunakan untuk membentuk pengasuhan yang berkualitas menuju keluarga yang bahagia dan sejahtera. Sayangnya, pada kenyataannya masih banyak Penyuluh Keluarga Berencana yang belum mengetahui tentang konsep dan praktik disiplin positif dalam pengasuhan dikarenakan belum adanya modul mengenai Disiplin Positif yang dapat dipelajari (Wawancara personal dengan salah satu Widyaiswara BKKBN, Maret 2018).

Oleh karena itu, untuk membekali dan menunjang kinerja Penyuluh Keluarga Berencana dalam memberikan informasi, mengedukasi dan melatih masyarakat mengenai penerapan disiplin positif dalam mengasuh anak, maka peneliti menyusun modul Pelatihan Disiplin Positif dengan konten materi yang cakupannya tidak terlalu luas yaitu fokus pada strategi teknik disiplin tanpa kekerasan yang efektif berdasarkan prinsip disiplin positif dari Nelsen (2008). Selain itu, agar pembelajaran dalam pelatihan dapat berjalan optimal 
maka penyampaian modul Pelatihan Disiplin Positif yang disusun menggunakan metode experiential learning. Melalui metode ini, pengetahuan diperoleh dari pengalaman yang didapatkan dengan melakukan berbagai aktivitas dan dengan melalui siklus mengalami, membagikan, memproses, menyimpulkan dan menerapkan dalam kehidupan sehari-hari (Kolb \& Kolb, 2008).

Agar modul yang disusun dapat dipertanggungjawabkan secara ilmiah maka modul harus divalidasi. Oleh karena itu, tujuan dari penelitian ini adalah untuk memvalidasi modul Pelatihan Disiplin Positif yang dapat digunakan oleh Penyuluh Keluarga Berencana untuk meningkatkan praktik pengasuhan disiplin positif pada ibu yang memiliki anak prasekolah.

\section{Metode}

\section{Partisipan penelitian}

Partisipan penelitian ini berjumlah 16 orang (8 orang menjadi kelompok kontrol dan 8 orang menjadi eksperimen). Penentuan sampel dilakukan dengan teknik purposive sampling dengan kriteria inklusi sebagai berikut: (1) ibu yang memiliki anak prasekolah (usia anak 3 - 5 tahun); (2) usia ibu berkisar 23 - 40 tahun; (3) berpendidikan minimal SMA atau sederajat; (4) memiliki skor praktik pengasuhan disiplin positif sedang atau rendah yang diukur menggunakan Skala Praktik Pengasuhan Disiplin Positif; (5) ibu dan anak tinggal dalam satu rumah; (6) tidak sedang mengikuti kegiatan pelatihan pengasuhan sejenis selama proses pengukuran dan pelatihan; (7) bersedia untuk berpartisipasi pada keseluruhan rangkaian pelatihan dan penelitian dengan menandatangani informed consent.

\section{Instrumen penelitian}

Modul Pelatihan Disiplin Positif. Modul disusun berdasarkan prinsip-prinsip disiplin positif yang dikembangkan oleh Nelsen (2008) yang terdiri dari 1) lembut dan tegas pada waktu yang bersamaan (kind and firm) dengan saling menghormati dan memberikan dorongan, 2) memahami tujuan dari perilaku anak yang tidak sesuai, 3) melibatkan anak dalam memecahkan permasalahan dan fokus pada solusi, 4) mencoba untuk terhubung dengan anak sebelum memberikan perbaikan, dan 5) kesalahan merupakan sebuah kesempatan untuk belajar dalam mengasuh anak.

Dalam pelaksanaannya, penggunaan metode pembelajaran experiential learning pada Pelatihan Disiplin Positif melibatkan berbagai aktivitas. Aktivitas tersebut didasarkan pada mekanisme perubahan aktif dan interaktif seperti pekerjaan rumah, pemodelan, atau praktik. Secara empiris, pelatihan pengasuhan yang menggunakan metode pembelajaran experiential learning terbukti memiliki efek yang tinggi dan konsisten terhadap keberhasilan pelatihan (Saunders, McFarland-Piazza, Jacobivitz, Hazen-Swann, \& Burton, 2012). Melalui aktivitas yang dilakukan, peserta diajak untuk mengalami sebuah pengalaman, membagikan pengalaman yang didapatkan, memproses pengalaman yang ada, menyimpulkan dan harapannya nantinya peserta mampu menerapkannya dalam kehidupan sehari-hari.

\section{Tes Pengetahuan Disiplin Positif.} Instrumen digunakan untuk mengetahui pengetahuan pengasuhan berdasarkan konsep disiplin positif yang dimiliki oleh 
seseorang. Tes ini disusun berdasarkan materi dan prinsip disiplin positif yang disampaikan dalam Pelatihan Disiplin Positif. Tes ini berisi pernyataan yang memiliki jawaban benar atau salah sebanyak 32 aitem. Alat ukur telah diujicobakan pada 187 ibu yang memiliki anak prasekolah. Hasil analisis menunjukkan bahwa koefisien reliabilitas alpha Cronbach alat ukur adalah 0,788 dengan tingkat kesukaran aitem berkisar dari 0,246-0,952 dan daya beda aitem berkisar antara 0,330-0,791.

\section{Skala Praktik Pengasuhan Disiplin Positif.} Instrumen ini disusun berdasarkan praktikpraktik pengasuhan yang sesuai dengan konsep disiplin positif dari Nelsen (2008). Skala Praktik Pengasuhan Disiplin Positif terdiri dari 40 aitem dalam bentuk rating scale yang dimulai dari skor 1 hingga 5 . Semakin tinggi skor, maka semakin tinggi praktik pengasuhan disiplin positif yang dilakukan oleh partisipan. Untuk mengetahui validitas isi skala, sebelum digunakan Skala Praktik Pengasuhan Disiplin Positif terlebih dahulu dinilai oleh 7 orang professional judgement (2 orang dosen dan 5 orang Psikolog). Hasil perhitungan yang diperoleh dari professional judgement melalui rumus Aiken's $V$, didapatkan nilai koefisien validitas alat ukur berada pada rentang 0,68-0,89 ( $V>$ $0,5)$. Sehingga dapat disimpulkan bahwa semua aitem pada Skala Praktik Pengasuhan Disiplin Positif memiliki koefisien validitas isi yang baik dan setiap aitem skala mendukung validitas isi skala secara keseluruhan. Alat ukur telah diujicobakan pada 188 ibu yang memiliki anak prasekolah. Hasil analisis menunjukkan bahwa koefisien reliabilitas
Skala Praktik Pengasuhan Disiplin Positif adalah 0,96 dengan koefisien korelasi aitem total sebesar 0,303-0,672.

\section{Desain penelitian}

Metode yang digunakan dalam penelitian ini adalah quasi experiment. Rancangan penelitian menggunakan untreated control group design with dependent pretest and posttest samples (Shadish, Cook, \& Campbell, 2002). Desain eksperimen menggunakan dua kelompok (between subject design) yang terdiri atas kelompok pertama sebagai kelompok eksperimen dan kelompok kedua sebagai kelompok kontrol. Penempatan partisipan ke dalam kedua kelompok menggunakan teknik non-randomize, partisipan yang bersedia mengikuti pelatihan secara penuh menjadi kelompok eksperimen, sedangkan yang tidak bersedia menjadi kelompok kontrol.

\section{Prosedur penelitian}

Penelitian yang dilakukan melalui prosedur sebagai berikut: 1) studi pendahuluan, meliputi wawancara dan pengamatan dengan psikolog puskesmas dan beberapa ibu yang memiliki anak prasekolah, focus group discussion terhadap orang tua mengenai pengasuhan dan wawancara kepada Widyaiswara BKKBN terkait kebutuhan akan adanya modul pelatihan pengasuhan yang dapat digunakan oleh Penyuluh Keluarga Berencana; 2) mengikuti Pelatihan Disiplin Positif secara online; 3) persiapan penelitian, meliputi penyusunan program dan modul pelatihan, buku materi dan buku kerja untuk partisipan, penyusunan lembar observasi, pembuatan lembar evaluasi pelaksanaan, penyusunan dan uji coba tes pengetahuan disiplin positif, penyusunan dan uji coba skala praktik pengasuhan disiplin positif, serta 
pemilihan trainer dan observer; dan 4) pelaksanaan penelitian, meliputi validasi isi dan validasi fungsional. Validasi isi digunakan untuk memastikan apakah modul yang disusun adalah valid, tidak terbatas pada makna tercapai-tidaknya tujuan pemberian intervensi saja, tetapi mencakup juga makna keselarasan antara isi materi yang diberikan dalam pelatihan dengan tujuannya (Azwar, 2017).

Validasi isi meliputi penilaian oleh professional judgement terhadap materi, metode, media, aktivitas, lembar kerja dan waktu yang digunakan dalam modul. Validasi isi juga dilakukan dengan melakukan uji keterbacaan dan pemahaman (Susilana \& Riyana, 2009). Uji keterbacaan dan pemahaman meliputi penilaian oleh Widyaiswara dan Penyuluh Keluarga Berencana terhadap bahasa yang digunakan dalam modul dapat dipahami dengan baik oleh Penyuluh Keluarga Berencana atau tidak. Sedangkan validasi fungsional adalah validasi yang ditujukan untuk memastikan bahwa modul intervensi memang berfungsi secara empirik sesuai dengan tujuannya (Azwar, 2017). Validasi fungsional ini meliputi (1) training of trainer (ToT) Pelatihan Disiplin Positif oleh Psikolog kepada Penyuluh Keluarga Berencana yang dilaksanakan selama 3 hari dengan durasi sekitar 5 jam setiap pertemuan; (2) training of trainer (ToT) Pelatihan Disiplin Positif oleh Penyuluh Keluarga Berencana pada Ibu Anak Prasekolah yang dilakukan dalam 4 pertemuan yang memuat 8 sesi. Setiap pertemuan memuat 2 sesi dengan durasi kurang lebih 4,5 jam. Empat pertemuan tersebut dilaksanakan dalam waktu 4 hari dengan jeda 1-2 hari agar peserta mampu mempraktikan tugas rumah yang diberikan.
Analisis data

Metode yang digunakan dalam analisis data pada penelitian ini adalah metode kuantitatif dan kualitatif. Analisis data secara kuantitatif menggunakan uji Mann Whitney $U$ untuk menguji perbedaan skor posttest antara kelompok eksperimen dan kelompok kontrol. Sebagai analisis tambahan dilakukan Wilcoxon signed rank test untuk menguji perbedaan pretest-posttest pada kelompok eksperimen. Analisis kualitatif dilakukan melalui hasil Focus Group Discussion (FGD), observasi dan buku kerja pelatihan yang diisi sendiri oleh partisipan.

\section{Hasil}

\section{Validasi isi modul dengan tujuan modul}

Nilai koefisien validitas isi modul dengan tujuan modul yang diperoleh dari hasil penilaian dari 6 orang professional rater (5 orang psikolog dan 1 orang dosen) berada pada rentang 0,75-0,958 $(V>0,5)$. Hal tersebut menunjukkan bahwa dari sisi tujuan, isi modul secara umum, materi, waktu pelaksanaan, pemberian tugas, bentuk lembar kerja yang digunakan dalam modul Pelatihan Disiplin Positif memiliki nilai validitas isi yang baik.

\section{Validasi keterbacaan isi modul}

Nilai koefisien validitas keterbacaan isi modul bagi Penyuluh Keluarga Berencana yang diperoleh dari 5 orang professional judge (2 orang Widyaiswara dan 3 orang Penyuluh Keluarga Berencana dengan tingkat pendidikan minimal S-1 dan lama bekerja minimal 5 tahun) berada pada rentang 0,70-0,95. Hasil tersebut menunjukkan bahwa Penyuluh Keluarga Berencana dapat mengerti dan memahami bahasa, instruksi, prosedur pelaksanaan, 
materi, substansi tugas rumah dan bentuk lembar kerja yang ada pada modul Pelatihan Disiplin Positif dengan baik.

\section{Validasi training of trainer (ToT)}

Hasil analisis uji Wilcoxon menunjukkan adanya perbedaan yang signifikan antara hasil pretest dan posttest tes pengetahuan dan wawancara disiplin positif pada Penyuluh Keluarga Berencana. Hal tersebut ditunjukkan dengan nilai $Z$ sebesar -2,032 dengan nilai signifikansi sebesar 0,042 $(p<$ $0,05)$ pada Tes Pengetahuan Disiplin positif dan $Z$ sebesar $-2,023$ dengan nilai signifikansi sebesar 0,043 $(p<0,05)$ pada wawancara. Dengan kata lain, dapat disimpulkan bahwa ToT Disiplin Positif dapat meningkatkan pengetahuan disiplin positif Penyuluh Keluarga Berencana.

Efek Pelatihan Disiplin Positif bagi ibu yang memiliki anak prasekolah

Untuk menguji apakah praktik pengasuhan disiplin positif antara kelompok kontrol dan kelompok eksperimen dalam penelitian ini memiliki varians yang homogen atau tidak maka dilakukan uji homogenitas. Hasil uji homegenitas menunjukkan nilai Asymp. Sig. (2-tailed) sebesar 0,855 ( $p>0,05)$ yang berarti bahwa sebelum intervensi diberikan, baik kelompok kontrol maupun kelompok eksperimen pada kondisi yang setara (equal) dalam hal praktik pengasuhan disiplin positif.

Pada penelitian ini, tes pengetahuan disiplin digunakan sebagai cek manipulasi. Hasil uji Wilcoxon menunjukkan adanya perbedaan yang signifikan antara hasil pretest dan posttest pada kelompok eksperimen. Hal tersebut ditandai dengan nilai $Z$ pada kelompok eksperimen yaitu sebesar -2,524 dengan nilai signifikansi sebesar 0,012 ( $p<0,05)$. Hal tersebut menunjukkan bahwa manipulasi yang dilakukan oleh peneliti dalam eksperimen berhasil.

Untuk mengetahui perbedaan skor Praktik Pengasuhan Disiplin Positif pada kelompok eksperimen dan kelompok kontrol dilakukan uji Mann Whitney $U$. Hasil uji Mann Whitney menunjukkan nilai $U$ sebesar 0,000 dengan nilai $Z=-3,363$ dan nilai asymp.Sig (2-tailed) adalah 0,001 ( $p<$ $0,05)$. Hasil tersebut mengindikasikan adanya perbedaan skor praktik pengasuhan disiplin positif antara kelompok eksperimen dan kelompok kontrol.

Berdasarkan hasil uji signed rank Wilcoxon dapat disimpulkan bahwa terdapat perbedaan tingkat praktik pengasuhan disiplin positif yang signifikan antara skor pretest dengan posttest pada kelompok eksperimen yang dibuktikan dengan nilai $Z=-2.524^{\mathrm{b}}$ dan nilai signifikansi $0,012(p<0,05)$. Sementara itu, pada kelompok kontrol tidak terdapat perbedaan tingkat praktik pengasuhan disiplin positif yang signifikan antara skor pretest dengan posttest yang dibuktikan dengan nilai $Z=-0.085^{\mathrm{b}}$ dan nilai signifikansi $0,933(p>0,05)$. Hal tersebut semakin menguatkan bahwa adanya perbedaan tingkat praktik pengasuhan disiplin positif dikarenakan adanya Pelatihan Disiplin Positif yang diberikan pada kelompok eksperimen.

\section{Hasil analisis data kualitatif}

Telah dijelaskan sebelumnya bahwa data kualitatif diperoleh melalui FGD, observasi dan buku kerja Pelatihan Disiplin Positif. Berdasarkan hasil FGD diperoleh beberapa informasi sebagai berikut: (1) setelah mengikuti Pelatihan Disiplin Positif, partisipan merasa pengetahuan dan wawasannya mengenai disiplin positif 
meningkat. Hal tersebut mendorong partisipan untuk meningkatkan praktik pengasuhan disiplin positif dalam mengasuh anak; (2). regulasi emosi dan dukungan dari pasangan dalam pengasuhan merupakan hal yang penting untuk menunjang seorang ibu dalam memberikan praktik pengasuhan disiplin positif pada anak.

Di sisi lain, hasil observasi dan buku kerja Pelatihan Disiplin Positif yang diisi oleh partsipan dapat disimpulkan bahwa partisipan memiliki kesiapan dan kemauan untuk mengikuti kegiatan Pelatihan Disiplin Positif dengan baik. Adanya kesiapan dan kemauan yang baik tersebut menunjang partisipan untuk lebih mudah dalam memahami materi dan mencoba untuk mempraktikkan pengasuhan disiplin positif yang diberikan dalam Pelatihan Disiplin Positif.

\section{Diskusi}

Berdasarkan hasil analisis data, dapat diketahui bahwa Pelatihan Disiplin Positif dapat meningkatkan pengetahuan dan Praktik Pengasuhan Disiplin Positif. Hasil penelitian ini mendukung hasil penelitian sebelumnya yang mengemukakan bahwa melalui pelatihan disiplin positif orang tua menjadi lebih tahu mengenai perkembangan anak dan pengasuhan yang berkualitas, menunjukkan kemampuan komunikasi yang lebih baik dalam memberikan batasan pada anak, mampu mengarahkan anak tanpa kekerasan (Ródenas et al., 2014) serta meningkatkan pola pengasuhan otoritatif dan menurunkan pola pengasuhan permisif dan otoriter (Holliday, 2014).

Lebih lanjut, adanya peningkatan pengetahuan yang diikuti dengan meningkatnya praktik pengasuhan pada penelitian ini selaras dengan hasil penelitian yang mengungkapkan bahwa pengetahuan akan pengasuhan memiliki peran penting dalam menentukan baik buruknya praktik pengasuhan yang akan dilakukan (Johnson, et al, 2006). Orang tua yang memiliki pengetahuan pengasuhan yang baik diprediksi lebih mampu melakukan praktik pengasuhan yang lebih positif (Bornstein, 2016; Siegel \& McGillicuddy-De Lisi, 2002) dikarenakan pengetahuan merupakan pedoman yang digunakan oleh orang tua dalam melakukan pengasuhan anak (Hickson \& Clayton, 2002).

Dari segi materi dan kegiatan yang terdapat dalam Pelatihan Disiplin Positif, berdasarkan hasil FGD dan isian pada buku kerja diperoleh hasil bahwa selain pengetahuan, kemampuan regulasi emosi dan cara melakukan relaksasi dianggap oleh partisipan sebagai hal yang perlu dikuasai oleh orang tua agar dapat menerapkan praktik pengasuhan disiplin positif. Hasil penelitian tersebut tidak ditemukan pada penelitian Holliday (2014) yang sama-sama menggunakan konsep disiplin positif dari Nelsen (2008) dalam pelatihan pengasuhan bagi orang tua. $\mathrm{Hal}$ tersebut dikarenakan dalam konsep disiplin positif yang dikembangkan baik oleh Nelsen (2008) maupun Durrant (2013) pada dasarnya memang tidak memuat materi yang membahas mengenai regulasi emosi dan cara melakukan relaksasi. Namun dengan melihat hasil penelitian ini, dapat disimpulkan bahwa dalam pelatihan pengasuhan bagi orang tua yang menggunakan konsep disiplin positif, materi mengenai regulasi emosi dan cara melakukan relaksasi sangat penting untuk ditambahkan. 
Pentingnya penambahan materi mengenai regulasi emosi sesuai dengan hasil penelitian yang menunjukkan bahwa ibu yang memiliki anak prasekolah penting untuk memiliki kemampuan mengelola emosi yang baik dikarenakan mengasuh anak prasekolah seringkali menguras energi baik fisik dan psikis yang menyebabkan orang tua merasa mudah marah dan sulit mengontrol emosi (Bögels, Lehtonen, dan Restifo, 2010). Dengan adanya kemampuan mengelola emosi yang baik akan membuat orang tua mampu berpikir rasional, mampu mengakses pengetahuan yang dimiliki sehingga orang tua mampu memberikan pengasuhan yang tepat (Ciciolla, Crnic, \& West, 2013; Crnic, Gaze \& Hoffman, 2005).

Dari penelitian ini juga didapatkan informasi bahwa kendala yang sering dihadapi oleh partisipan ketika berusaha menerapkan pengasuhan yang baik adalah dari sisi kurangnya dukungan dari pasangan ataupun anggota keluarga lainnya yang tinggal bersama-sama dalam satu rumah. Kurangnya dukungan dari orang-orang terdekat ini menyebabkan partisipan merasa melakukan peran pengasuhan seorang diri, merasa kurang dihargai sehingga seringkali membuat partisipan menjadi mudah stress dan merasa sulit untuk memberikan pengasuhan yang baik. Adanya hal tersebut pada akhirnya membuat partisipan merasa tidak termotivasi untuk memberikan pengasuhan yang berkualitas pada anakanak mereka (Ensor \& Hughes, 2010). Oleh karena itu, penyadaran dan penyamaan pandangan akan pengasuhan yang baik dengan pasangan (coparenting) dan keluarga menjadi hal yang sangat penting. Teubert dan Pinquart (2010) menyatakan bahwa coparenting merupakan bagian yang penting yang menunjang terciptanya pengasuhan yang berkualitas pada anak.

Perbedaan penelitian ini dengan penelitian pemberian pelatihan pengasuhan pada orang tua sebelumnya adalah pada variabel independen yang diukur. Pada penelitian ini, variabel dependen yang diukur adalah praktik pengasuhan. Sementara pada penelitian-penelitian lain mengenai pemberian pelatihan pengasuhan pada orang tua yang peneliti temukan di Fakultas Psikologi UGM variabel dependen yang diukur sebagian besar adalah pola pengasuhan (Efnita, 2014; Permata, 2017; Subekti, 2010).

Dalam penelitiannya, Holliday (2014) menyatakan bahwa perubahan pola pengasuhan dapat diukur setidaknya 2-3 bulan setelah pelatihan pengasuhan bagi orang tua diberikan. Akan tetapi pada beberapa penelitian di atas yang mengukur pola asuh, peneliti menemukan bahwa pengukuran perubahan pola asuh dilakukan dengan jeda waktu yang tidak terlalu lama dari setelah pemberian pelatihan. Merujuk pada pernyataan Holliday (2014) di atas, maka hasil perubahan pola pengasuhan pada penelitian tersebut masih dapat diperbedatkan. Melalui penelitian ini, alihalih mengukur perubahan pola pengasuhan yang terlalu dekat dengan pemberian intervensi, nampaknya mengukur praktik pengasuhan sebagai variabel dependen lebih memungkinkan. Hal tersebut dikarenakan praktik pengasuhan mencakup apa yang benar-benar atau senyatanya orang tua lakukan (seperti menampar, memeluk) yang terlihat secara konkret dalam situasi membesarkan anak dan lebih cepat berubah daripada pola pengasuhan (Darling \& Steinberg, 1993). Oleh karena itu, praktik pengasuhan dapat diukur 
dalam waktu dekat ( \pm 2 minggu) setelah pemberian pelatihan pengasuhan.

Sebagaimana yang telah dijelaskan sebelumnya, isi modul Pelatihan Disiplin Positif mengacu pada Positive Discipline Workbook: Facilitators Guide yang telah digunakan secara luas di Amerika dengan trainer non Psikolog (Nelsen, 2008). Pada penelitian ini, trainer Pelatihan Disiplin Positif juga bukan psikolog melainkan Penyuluh Keluarga Berencana. Penggunaan trainer yang bukan psikolog sebelumnya jarang dilakukan pada penelitian pelatihan pengasuhan bagi orang tua yang ada di Fakultas Psikologi UGM (Efnita, 2014; Permata, 2017; Subekti, 2010). Adanya pelibatan Penyuluh Keluarga Berencana sebagai trainer pelatihan Disiplin Positif diharapkan dapat semakin memperluas penggunaan modul Pelatihan Disiplin Positif di masyarakat dikarenakan di setiap desa/kelurahan setidaknya terdapat satu orang Penyuluh Keluarga Berencana.

Sebagai upaya agar Penyuluh Keluarga Berencana memenuhi kompetensi trainer Pelatihan Disiplin Positif, maka pada penelitian ini dilakukan training of trainer (ToT) Pelatihan Disiplin Positif yang dilakukan oleh Psikolog pada Penyuluh Keluarga Berencana (PKB). Adapun kompetensi yang hendak dicapai dari proses ToT adalah untuk memastikan bahwa Penyuluh Keluarga Berencana memiliki pengetahuan dan penguasaan yang baik mengenai materi yang akan disampaikan dan memiliki kemampuan komunikasi yang efektif dalam menyampaikan informasi pada peserta pelatihan. Gauld (2015) mengungkapkan bahwa kedua kompetensi tersebut merupakan kompetensi penting yang harus dimiliki oleh trainer untuk menunjang keberhasilan pelatihan.
Hasil dari ToT dan pelaksanaan Pelatihan Disiplin Positif pada Ibu yang memiliki anak prasekolah menunjukkan bahwa Penyuluh Keluarga Berencana mampu untuk menjadi trainer Pelatihan Disiplin Positif dengan baik. Penyuluh Keluarga berencana mampu memberikan informasi yang mudah dipahami dan dapat memandu proses pelatihan dengan baik dan menarik. Hal ini ditunjukkan dari evaluasi partisipan pelatihan yang merasa puas dengan pelatihan yang diberikan. Selain itu partisipan juga tidak mengeluh terhadap waktu pelatihan yang berlangsung cukup lama (4,5 jam setiap pertemuan). Tidak hanya itu, partisipan penelitian juga mengungkapkan keinginannya untuk kembali diundang apabila ada lanjutan dari kegiatan ini atau jika ada kegiatan yang sejenis.

Penggunaan metode pembelajaran experiential learning dinilai efektif dan turut menyumbang keberhasilan pelatihan. Melalui proses diskusi, brainstorming, dan roleplay partisipan mendapatkan berbagai pengalaman dan membantu partisipan untuk mencapai insight atas kesalahan praktik pengasuhan yang selama ini dilakukan dan apa yang selanjutnya harus dilakukan untuk memperbaiki kesalahan pengasuhan yang terlanjur sudah dilakukan.

Sementara itu melalui proses membagikan pengalaman (publishing/ sharing) selain partisipan dapat belajar dari pengalaman partisipan lain, partisipan juga merasa mendapatkan dukungan moral dari partisipan lain untuk dapat menerapkan pengasuhan disiplin positif pada anak mereka. Dukungan dari partisipan lain dalam Pelatihan Disiplin Positif merupakan dukungan sosial yang merupakan sumber daya psikologis yang dapat menimbulkan 
adanya perasaan positif karena merasa tidak sendirian, diakui dan dihargai oleh orang lain (Bornstein, 2007).

Guna mendukung proses applying, pelaksanaan Pelatihan Disiplin Positif dirancang dengan ada jeda setidaknya satu hari untuk memberi kesempatan praktikan menerapkan praktik pengasuhan yang diperoleh dari pelatihan di rumah dengan anak mereka. Penerapan hasil belajar dalam bentuk perilaku nyata tersebut menjadi pengalaman (experiencing) bagi partisipan bahwa menerapkan pengasuhan disiplin positif tidak dapat langsung dapat berjalan dengan sempurna dan memerlukan proses yang panjang. Namun demikian, dari proses applying ini, partisipan memperoleh pemahaman bahwa untuk menerapkan pengasuhan disiplin positif diperlukan kesabaran dan kekonsistenan.

Penelitian ini bukan tanpa keterbatasan. Salah satu keterbatasan dalam penelitian ini adalah pada karakteristik partisipan penelitian. Meskipun pada saat rekrutmen partisipan sudah disampaikan bahwa penelitian ini dapat diikuti oleh ibu dengan tingkat pendidikan Sekolah Menengah Atas (SMA), akan tetapi yang mendaftar untuk mengikuti penelitian ini sebagian besar adalah ibu dengan tingkat pendidikan sarjana/S-1. Tidak adanya follow up juga menjadi keterbatasan dalam penelitian ini dikarenakan dari informasi mengenai jangka waktu efek pemberian pelatihan tidak dapat diketahui. Dari sisi trainer dengan Penyuluh Keluarga Berencana juga mengandung keterbatasan. Pada penelitian ini, Pelatihan Disiplin Positif yang diuji baru melibatkan Penyuluh Keluarga Berencana yang berjenis kelamin perempuan. Oleh karena itu, penggunaan modul Pelatihan Disiplin Positif pada Penyuluh Keluarga Berencana dengan jenis kelamin laki-laki masih belum dapat diketahui apakah berhasil atau tidak.

Keterbatasan yang lain adalah adanya ancaman validitas internal meliputi faktor history, maturity, dan testing (Shadish, Cook, Campbell, 2002). Faktor history berkaitan dengan peristiwa yang terjadi selama proses pelatihan berlangsung yang tidak dapat dikontrol oleh peneliti dan dapat berpengaruh pada hasil penelitian. Kondisi ini menyebabkan peneliti tidak dapat menjamin sepenuhnya bahwa terjadinya perubahan pada praktik pengasuhan disiplin positif tidak hanya disebabkan oleh perlakuan yang diberikan tetapi juga dipengaruhi oleh faktor sejarah maupun pengalaman subjek penelitian atau masalah-masalah lain yang berhubungan dengan pengasuhan. Sumber keterbatasan penelitian lainnya yaitu berasal dari faktor maturation atau kematangan yang berkaitan dengan perubahan secara biologis maupun psikologis pada partisipan. Perubahan (kematangan) yang dialami partisipan akan berpengaruh terhadap variabel dependen (praktik pengasuhan disiplin positif) yang diukur dalam penelitian ini. Oleh karenanya, perubahan yang terjadi tidak hanya disebabkan oleh perlakuan atau pelatihan yang diberikan, namun juga dapat disebabkan karena proses kematangan pada partisipan mendapatkan perlakuan tersebut. Akan tetapi, hal ini telah diantisipasi oleh peneliti yaitu dengan menggunakan kelompok kontrol sebagai kelompok pembanding. Keterbatasan lainnya yaitu dari faktor testing. Pada penelitian ini dilakukan pengukuran sebanyak dua kali pada kelompok eksperimen dan kelompok kontrol. Hal ini menyebabkan kemungkinan adanya efek belajar pada partisipan yang menjadikan partisipan terbiasa dalam mengerjakan 
skala yang diberikan. Kondisi ini diantisipasi oleh peneliti dengan cara menekankan kepada partisipan untuk mengisi skala yang diberikan dengan sebenar-benarnya sesuai dengan kondisinya saat dilakukan pengukuran tersebut.

Adapun kelemahan lainnya yaitu dari sisi analisis data, penelitian ini menggunakan statistika non-parametrik. Salah satu keterbatasan statistika non parametrik adalah pada suatu aspek yang disebut power efficiency. Analisis statistika non-parametrik pada umumnya memiliki power efficiency yang lebih rendah dibandingkan analisis statistika parametrik (Azwar, 2016).

\section{Kesimpulan}

Hasil dari penelitian yang dilakukan menunjukkan bahwa Modul Pelatihan Disiplin Positif memiliki validitas isi dan validitas fungsional yang baik. Dengan demikian dapat disimpulkan bahwa Modul Pelatihan Disiplin Positif terbukti valid dapat digunakan oleh Penyuluh Keluarga Berencana untuk meningkatkan praktik pengasuhan disiplin positif pada ibu yang memiliki anak prasekolah.

\section{Saran}

Beberapa hal yang dapat peneliti sarankan yaitu: 1) modul Pelatihan Disiplin Positif ini dapat digunakan sebagai salah satu acuan oleh Penyuluh Keluarga Berencana dalam memberikan pelatihan pengasuhan penerapan disiplin positif bagi ibu yang memiliki anak prasekolah di wilayah kerjanya; 2) agar Modul Pelatihan Disiplin Positif ini semakin baik maka masih perlu untuk diujicobakan pada partisipan dengan tingkat pendidikan sekolah menengah atau lebih rendah, diujicobakan dengan melibatkan lebih banyak partisipan dan diujicobakan dengan trainer Penyuluh Keluarga Berencana yang berjenis kelamin laki-laki; 3) selain adanya modul Pelatihan Disiplin Positif bagi ibu yang memiliki anak prasekolah diperlukan juga pelatihan pengasuhan yang sejenis terutama untuk ayah. Hal tersebut mengingat bahwa dalam memberikan pengasuhan pada anak, ibu sangat memerlukan dukungan sosial dari anggota keluarga lain terutama suami dan proses pengasuhan yang ideal yaitu yang melibatkan kedua orang tua.

\section{Kepustakaan}

Alegre, A. (2012). The relation between the time mothers and children spent together and the children's trait emotional intelligence. Child and Youth Care Forum, 41(5), 493-508. doi: 10.1007/s10566-012-9180-Z

Azwar, S. (2016). Aplikasi mudah statistika non-parametrik. Yogyakarta: Pustaka Pelajar

Azwar, S. (2017). Metode penelitian psikologi. Yogyakarta : Pustaka Pelajar

Badan Kependudukan dan Keluarga Berencana Nasional (BKKBN). (2014). Pedoman pelaksanaan penggerakkan lini lapangan program kependudukan, Keluarga Berencana dan pembangunan keluarga tahun 2014. Jakarta: Badan Kependudukan dan Keluarga Berencana Nasional. Diunduh melalui http://jdih.bkkbn.go.id/public assets/f ile/ca0f9b8002b3d921 afe8b7577bda3c0d.pdf (pada 28 Maret 2018)

Bögels, S. M., Lehtonen, A., \& Restifo, K. (2010). Mindful parenting in mental health care. Mindfulness, 1(2), 107-120. doi: $\underline{10.1007 / \mathrm{s} 12671-010-0014-5}$ 
Bögels, S., \& Restifo, K. (2014). Mindful parenting: A guide for mental health practitioners . New York: Springer.

Bornstein, M. H. (2007). Parenting science and practice. In K. A. Renninger \& I. E. Sigel (Eds.). Handbook of child psychology: Child psychology in practice (Vol. 4, pp. 893-949). New Jersey: John Wiley \& Sons.

Bornstein, M. H. (2016). Determinants of parenting. In D. Chicchetti (Ed.). Developmental psychopathology volume 4: Risk, resilience, and intervention (Edisi ketiga, pp. 180-239). New Jersey: John Wiley \& Sons.

Ciciolla, L., Crnic, K. A., \& West, S. G. (2013). Determinants of change in maternal sensitivity: Contributions of context, temperament, and developmental risk. Parenting: Science and Practice, 13(3), 178-195. doi: $\underline{10.1080 / 15295192.2013 .756354}$

Crnic, K. A., Gaze, C., \& Hoffman, C. (2005). Cumulative parenting stress across the preschool period: Relations to maternal parenting and child behaviour at age 5. Infant and Child Development, 14(2), 117-132. doi: 10.1002/icd.384

Darling, N. \& Steinberg, L. (1993). Parenting style as context: An integrative model. Psychological Bulletin, 113(3), 487-496. doi: $\underline{10.1037 / 0033-2909.113 .3 .487}$

Durrant, J. E. (2013). Positive discipline in everyday parenting (Edisi ketiga). Sweden: Save The Children.

Efnita, S. (2014). Program pengasuhan positif untuk meningkatkan kualitas pengasuhan ibu (Tesis tidak dipublikasikan). Fakultas Psikologi Universitas Gadjah Mada, Yogyakarta.

Ensor, R., \& Hughes, C. (2010). With a little help from my friends: Maternal social support, via parenting, promotes willingness to share in preschoolers born to young mothers. Infant and Child Development, 19(2), 127-141. doi: $\underline{10.1002 / \text { icd.643 }}$

Gauld, D. (2015). The competencies of effective trainers and teachers. In $\mathrm{K}$. Kraiger, J. Passmore, N. R. Dos Santos, \& M. Sigmar (Ed.). Handbook of the psychology of training, development, and performance improvement (Edisi pertama, pp. 117-135). New Jersey : John Wiley \& Sons, Ltd.

Gfroerer, K. P., Nelsen, J., \& Kern, R. M. (2013). Positive discipline: Helping children develop belonging and coping resources using individual psychology. Journal of Individual Psychology, 69(4), 294-304.

Hasan, A., Hyson, M., \& Chang, E. (2013). Early childhood education and development in poor villages of Indonesia: Strong foundations, later success. Washington, DC: World Bank

Hickson, G. B., \& Clayton, E. W. (2002). Parents and their children's doctors. In M. H. Bornstein (Ed.), Handbook of parenting volume 5: Practical parenting (pp. 439-462). Mahwah, NJ: Lawrence Erlbaum Associates.

Holliday, M. J. (2014). Authoritative parenting and outcomes of positive discipline parent training: Parenting style and perceived efficacy (Disertasi). Diakses melalui ProQuest Dissertations and Theses database. (UMI No. 3662133)

Huey, E. L., Sayler, M. F., \& Rinn, A. N. (2013). Effects of family functioning and parenting style on early entrants' academic performance and program completion. Journal for the Education of the Gifted, 36(4), 418-432. doi: $\underline{10.1177 / 0162353213506066}$ 
Johnson, M. A., Stone, S., Lou, C., Ling, J., Claassen, J., \& Austin, M. J. (2006). Assessing parent education programs for families involved with child welfare service. Journal of EvidenceBased Sosial Work, 5(1), 191-238. doi: $\underline{10.1300 / / 394 v 05 \mathrm{n} 0108}$

Kementerian Hukum dan Hak Asasi Manusia Republik Indonesia. (2013). Peraturan Presiden Republik Indonesia Nomor 60 Tahun 2013 Tentang Pengembangan Anak Usia Dini HolistikIntegratif. Jakarta: Kementerian Hukum dan Hak Asasi Repubilk Indonesia. Diunduh dari https://www.banpaudpnf.or.id/uploa d/downloadcenter/Perpres $\% 20$ No.60 \%.20Tahun\%202013\%20tentang\%20P AUD\%20Holistik\%20Int 150875293.p df (pada 27 Maret 2018)

Kolb, A. Y., \& Kolb, D. A. (2008). Experiential learning theory: A dynamic, holistic approach to management learning, education and development. In Armstrong, S. J. \& Fukami, C. (Eds.). Handbook of management learning, education and development. London: Sage Publications

McKee, L., Colletti, C., Rakow, A., Jones, D. J., \& Forehand, R. (2008). Parenting and child externalizing behaviors: Are the associations specific or diffuse?. Aggression and Violent Behavior, 13(3), 201-215. doi: 10.1016/j.avb.2008.03.005

Mercy, J. A., \& Saul, J. (2009). Creating a healthier future through early interventions for children. Journal of the American Medical Association, 301(21), 2262-2264. doi: 10.1001/jama.2009.803

Nelsen, J. (2008). Positive discipline: The classic guide to helping children develop self-discipline, responsibility, cooperation and problem-solving kills. United States: Ballantine Books.

Olson, D. H., DeFrain, J.,\& Skogrand, L. (2014). Marriages and families: Intimacy, diversity, and strengths (Edisi kedelapan). United States of America: McGraw-Hill Education.

Permata, A. I. (2017). Pelatihan Pengasuhan "Aktif" untuk meningkatkan kualitas pengasuhan pada ibu yang memiliki anak usia dini (Tesis tidak dipublikasikan). Fakultas Psikologi Universitas Gadjah Mada, Yogyakarta.

Rinaldi, C. M., \& Howe, N. (2012). Mothers' and fathers' parenting styles and associations with toddlers' externalizing, internalizing, and adaptive behaviors. Early Childhood Research Quarterly, 27(2), 266-273. doi: 10.1016/j.ecresq.2011.08.001

Ródenas, F., Garcés, J., Durá, E., \& DoñateMartínez, A. (2014). Education and training for parents today, discipline and wellbeing for children tomorrow. Procedia-Social and Behavioral Sciences, 116, 2248 - 2251. doi: 10.1016/j.sbspro.2014.01.553

Sanders, M. R. (2008). Triple P-Positive parenting program as a public health approach to strengthening parenting. Journal of Family Psychology, 22(4), 506517. doi: $\underline{10.1037 / 0893-3200.22 .3 .506}$

Sanders, M. R. (2012). The knowledge of effective parenting scale ( KEPS ): A Tool for public health approaches to universal parenting programs. The Journal of Primary Prevention-Springer, 33(2-3), 85-97. doi: 10.1007/s10935-0120268-x

Santrock, J. W. (2013). Life span development (Edisi keempat belas). New York: McGraw-Hill. 
Sasongko, J. P. (2015, September 16). KPAI: Kekerasan anak dipicu buruknya pengasuhan orang tua. CNN Indonesia. Diakses melalui https://www.cnnindonesia.com/nasio nal/20150916103500-20-79056/kpaikekerasan-anak-dipicu-buruknyapengasuhan-orang-tua/ (pada 11 September 2007)

Saunders, R., McFarland-Piazza, L., Jacobvitz, D., Hazen-Swann, N., \& Burton, R. (2012). Maternal knowledge and behaviors regarding discipline: The effectiveness of a hands-on education program in Positive Guidance. Journal of Child and Family Studies, 22(3), 322-334. doi: 10.1007/s 10826-012-9581-5

Shadish, W. R., Cook, T. D., \& Campbell, D. T. (2002). Experimental and quasiexperimental designs for generalized causal inference. New York: Houghton Mifflin Company.

Siegel, I. E., \& McGillicuddy-De Lisi, A. V. (2002). Parental beliefs and cognitions: The dynamic belief systems model. In M. H. Bornstein (Ed.), Handbook of parenting: Status and social conditions of parenting (Edisi kedua, Vol. 3, pp. 485508). Mahwah, NJ: Lawrence Erlbaum Associates.

Situmorang, T. S. K. (2015). Perbedaan gangguan perilaku anak prasekolah berdasarkan pola pengasuhan (Tesis tidak dipublikasikan). Fakultas Kedokteran Universitas Gadjah Mada, Yogyakarta.

Subekti, A. R. (2010). Program pengasuhan positif untuk mengurangi aspek pola pengasuhan disfungsional (Tesis tidak dipublikasikan). Fakultas Psikologi Universitas Gadjah Mada, Yogyakarta.

Susilana, R., \& Riyana, C. (2009). Media pembelajaran hakikat, pengembangan, pemanfaatan dan penilaian. Bandung : Wacana Prima

Teubert, D., \& Pinquart, M. (2010). The association between coparenting and child adjustment: A meta-analysis. Parenting: Science and Practice, 10(4), 286-307. doi: $\underline{10.1080 / 15295192.2010 .492040}$

Tomlinson, H. B., \& Andina, S. (2015). Parenting education in Indonesia. Jakarta: World Bank. 